\title{
Corrigendum
}

\section{Pharmacologically Induced Hypogonadism and Sexual Function in Healthy Young Women and Men}

\author{
Peter J Schmidt, Emma M Steinberg, Paula Palladino Negro, Nazli Haq, Carolyn Gibson and \\ David R Rubinow
}

Neuropsychopharmacology (2009) 34, 8I6; doi:I0.I038/npp.2008.9I; published online 25 June 2008

Correction to: Neuropsychopharmacology advance online publication, 19 March, 2008; doi:10.1038/sj.npp.2008.24

In this article, page 5 , right column, fifth paragraph, line 2 , first sentence following run-in head ('Comparisons between those with high and low baseline DISF scores.') should be 'Women with low and high total DISF scores at baseline had significantly different responses to induced hypogonadism (Figure 2).' 